\title{
Evaluation of a school-based health education model in schistosomiasis: a randomized community trial
}

M. Kotb, ${ }^{1}$ M. Al-Teheawy, ${ }^{1}$ M. El-Setouhy ' and H. Hussein ${ }^{2}$

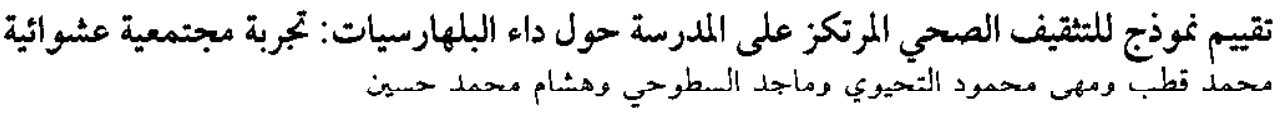

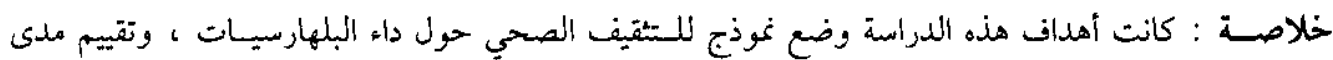

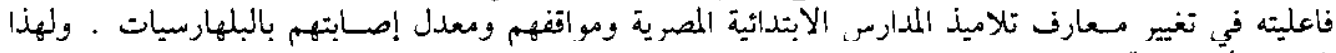

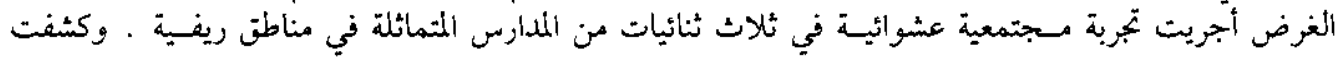

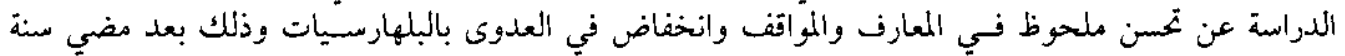

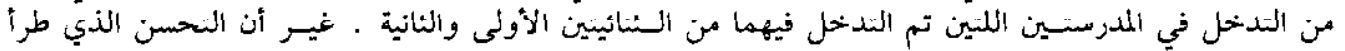

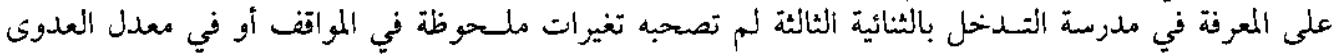
بالبلهارسيات

ABSTRACT The objectives of this study were to develop a schistosomiasis health education model and to evaluate ite effectiveness in changing knowledge, attitudos and schistosomal infoction rate among Egyptian primary school children. A randomized community trial of three pairs of comparable schools in rural areas was implemented. The study revealed a significant improvement in knowledge and attitudes as well as a reduction of schistosomal infection 1 year post-intervention in the intervention schools of pairs I and II. However, the improvements in knowledge in the intervention school of pair III were not accompanied by significant changes in attitude or schistosomal infection.

Evaluation d'un modele d'education sanitaire au niveau des ecoles dans le domaine de 1a schistosomiase: essai communautaire aléatoire

RESUME Les objectifs de cette étude étaient de mettre au point un modèle d'éducation sanitaire pour la schistosomiase et d'évaluer son efficacité sur le changemont dos connaissances, dos attitudes et du taux d'infestation schistosomienne chez des élèves du primaire en Egypte. On a procédé à un essai communautaire aléatoire avec trois paires d'écoles comparables en milieu rural. L'étude a révélé une amélioration sensible des connaissances et des attitudes ainsi qu'une réduction de l'infestation schistosomienne un an après l'intervention dans les écoles sites de l'intervention des paires I et II. Cependant, les améliorations des connaissances dans l'école site de l'intervention de la paire III ne sont pas accompagnées de changements importants dans les attitudes ou l'infestation schistosomienne.

'Department of Community Medicine; '2Department of Parasitology, Faculty of Medicine, Ain Shams University, Cairo. Egypt.

Received: 28/08/97; accepted:04/01/98

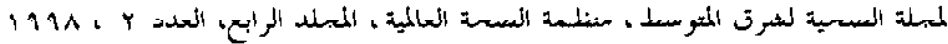




\section{Introduction}

Schistosomiasis is one of the leading public health problems in Egypt. It is predominantly a disease of rural populations and its highest incidence is among schoolchildren around 10 years of age $[1,2]$. The disease is largely caused by human behaviour, principally contamination and incorrect water use practices. Hence, health education is the cornerstone of control. The long-term effects of schistosomiasis control ineasures are assured by heath education and the provision of pure water supplies and sanitary facilities [3].

Schoolchildren are a major target for health education about schistosomiasis. This is because they play an important role in water contamination and infection transmission and because they are also susceptible to infection [4]. However, in Egypt there are no formal and systematic heath education activities directed towards schoolchildren. The report issued by the International Evaluation Mission of the Schistosmiasis Control Programme of Egypt indicated that schuolchildien in Egypt are not well exposed to schistosomiasis education [5].

This study had two objectives. The first was to develop a simple and practical school-based health education model for primary school children arousd the age of 10. The second was to compare its effectiveness on schistosomal knowledge and attitude, as well as infestation, 1 year after inserting the developed health education model into the routine screening and treatment activities of schoolchildren with that of routine screening and treatment activities alone.

\section{Methodology}

\section{Research setting}

This study was conducted in Kaliubia Governorate, northern Egypt. The overall prevalence of schistosumal infection in this governorate is about $20 \%$ [6]. The infection is mainly of Schistosoma mansoni type. This guvernorate was chosen for the current study for two reasons: its proximity to Cairo and the good cooperation with the team of the Directorate of Endemic Diseases.

\section{Selection of the study sites}

The sociodemographic information and the statistics of schistosomal infection in varjous villages in Kaliubia Governorate were reviewed. Three pairs of villages with differing levels of schistosomal infection were selected for the study. Each pair was comparable on the basis of its geographical location with relation to canals, the overall prevalence of schistosomal infection and its coverage with safe water supplies and sewage disposal systems.

Six primary sthools were chusen for evaluation of the effectiveness of the developed health education model. One school of each pair was subjected to the heallh education model, while the other member of the pair served as a comparison school. It was not feasible to include all the children of the six primary schools in the study because of limited funds. Accordingly, it was decided to restrict the study to the children in the fifth stage of primary education in the selected schools. Students in the fifth stage of primary education are about 10 years old, which is the peak age for schistosomal infection.

\section{Development of the study forms}

Six focus group discussion (FGD) sessions were conducted with the primary 
school children of the selected villages during July 1994 using established guidelines. Each session included an average of 15 children. This technique explored basic qualitative aspects pertaining to the knowledge and attitudes of the children regarding schistosomiasis, the wide range of water risks and contaminating practices as well as the prevailing misconceptions.

A preliminary version of the interview questionnaire was constructed as guided by the results of the FGD as well as those of relevant studies. The questionnaire contained five sections: sociodemographic questions; items to assess the children's knowledge of causative agents, sources of infection, modes of infection and major symptoms of schistosomiasis; items to assess the children's attitudes regarding water risks and contaminating behaviours; items to explore the wide range of water risks and contaminating behaviours of the study children; and finally, a record of the results of urine and stool examinations of the study children. This questionnaire was pre-tested and modified twice before being finalized.

The questionnaire included 21 items to assess the students' knowledge regarding modes of infection, life cycle, symptoms, complications and treatment. The items were designed to be short and clear and to contain only one idea in each statement. Correct answers were scored one point while incorrect answers were scored as zero.

Thirteen items were designed to assess the attitudes of the students toward the seriousness of the disease, safety of canal water, behaviours involving canal water and the prevention and control of schistosomiasis using a Likert scale with three grades $(1,0,-1)$. The sum of answers were considered to represent the degree of the students' overall attitudes toward schisto- somiasis. The Cronbach alpha coefficient was 0.84 and 0.73 for knowledge and attitude respectively, indicating an adequate level of the homogeneity of the used items. The items used in the knowledge and attitude score were reviewed and validated by a group of experts.

\section{Training interviewers and laboratory technicians}

A 2-day training course was provided to selected interviewers to familiarize them with the forms. The interviewers were university graduates who lived in the studied villages. A I-day refresher course was also provided to four assistant technicians to ensure that they knew the proper way to prepare urine and stool samples using the nucleopore filtration technique [7] and Kato method $[8]$ respectively.

\section{Baseline survey}

Collection of the baseline survey data using the established interview questionnaire was completed by February 1995. The survey included all schoolchildren in the fifth grade of education ( 800 students) from six primary schools located in three pairs of villages in Kaliubia Governorate. Urine and stool examinations were carried out using the nucleopore filtration technique and the Kato method. Microscopic examinations of the slides were conducted by highly qualified technicians under the supervision of an assistant professor of parasitology. All children found to be infected were treated with praziquantel $40 \mathrm{mg} / \mathrm{kg}$.

\section{Development of the health education model}

The contents of the schistosomiasis health education model for the schoolchildren were divided into three modules presented in three sessions over 3 days. Each session had its own objectives, sequence of events, 
strategies and evaluation. The modules were provided to the schoolchildren in the intervention schools on a class level as follows.

- The first module focused on orientation to the problem, water risks and contaminating practices.

- The second module was directed to the identification of the life cycle, symptoms and complications of schistosomiasis.

- The third module stressed the importance of healthy behaviour and of seeking medical care when necessary.

In general, the modei paid attention to basic facts regardless of their philosophical oricntation, as recommicnded by Loevinsohn [9]. The model included health talks, stories, case histories, role plays and drama. A package of slides, including exannples of real life situations, was developed and used to reinforce the presentation. A manual was also developed to help health educators discuss each slide and to achieve the objectives of each session.

\section{Training of school teachers}

Training continued for 4 days and was attended by 20 teachers officially working in the schools included in the study. It focused on basic principles of health education, bchavioural changes and communication skills. Application of these principles to the established schistosomal health education model was highly stressed. At the end of the training course, six teachers out of the 20 trainees were selected to provide the schistosomal schoolbased health education model.

\section{Implementation of the health education programme}

Within each pair of schools, one school was assigrıed to the health educatiou model while the other served as a control. Assignment was done randomly. Health education activities were conducted during March and April 1995.

\section{The tirst post-intervention survey}

The first post-intervention survey was conducted 1 month after implementing the health education programme. It included 212 children who represented a $50 \%$ systematic random sample of the children exposed to the health education model ( 424 children). The main objective was to assess early changes in knowledge and attitude.

\section{The second post-intervention survey}

The second post-intervention survey was conducted l year after intervention, during March and April 1996, using the same questionnaire and laboratory methods employed in the baseline survey. A total of 28 children were lost to follow-up from the intervention schools and 18 from the comparison schools.

\section{Statistical analysis}

Statistical analysis was performed using SPSS (version 5). All $P$ values were twotailed. Reliability was assessed with the Cronbach alpha coefficient, a measure of internal consistency [10]. Analysis of covariance was used to adjust the post-intervention knowledge and attitude for the possible confounding effect of variables whose distributions were significantly different during baseline statistical analysis.

\section{Results}

The baseline survey included the children in the fifth grade of education at six primary schools located in three pairs of villages in Kaliubia Governorate. The first pair included 212 and 154 children from El-Monera and 
Kafr El-Shourfa schools. The second pair comprised 119 and 149 children from Shoubra Shehab and Kafr Haleem schools respectively. The third pair involved 91 children from Behada school and 75 from Aghour school. Of the children in the intervention schools, $28(6.6 \%)$ were lost to follow-up for the final survey. The general characteristics of the drop-outs in each school were not significantly different from those who remained in the study. Similarly, the general characteristics of the 18 children $(4.8 \%)$ who dropped out from the comparison schools did not differ significantly from those who completed the study. As a result, loss to follow-up appears to have been non-differential.

Table I lists the general characteristics of the children in the study schools. The distribution of male children, children with illiterate fathers and availability of a toilet within the house were significantly higher in the intervention group versus its comparison school in pair I. For pair II, the presence of a toilet within the house was also significantly higher among children of the intervention school $(P<0.05)$. The distribution of illiterate mothers and sources of water supplies were comparable in the intervention and comparison schools of pairs I and II. The baseline prevalence of schistosomal infection in each of the study pairs was comparable $(27.4 \%$ and $22.7 \%$, $14.3 \%$ and $12.1 \%, 9.8 \%$ and $12.0 \%$ for the intervention and comparison schools of pairs I, II and III, respectively). However, the distribution of baseline characteristics was nearly similar in the intervention and comparison school of pair III. It is evident from Table 2 that the baseline knowledge and attitude scores were significantly different between the intervention and comparison school of pair I $(P<0.01)$. However. for pairs II and III the scores were nearly similar $(P>0.05)$.
The influence of the health education model on knowledge and attitude was assessed 1 month following implementation. Implementation was based on a $50 \%$ random sample of the children assigned to the health education model. The mean scores of both knowledge and attitude significantly improved $(P<0.001)$ indicating the potential value of the developed model (Table $3)$.

Analysis of covariance for the 1-year post-intervention knowledge score was conducted to evaluate the influence of the intervention and was adjusted for the possible confounding effect of sex, the level of the father's education, the availability of a toilet within house and the baseline knowledge score (Table 4). The effect of sex variation in pair I was significant. The main effect of variation in knowledge scores. however, was due to intervention. Variations between schools were highly significant in the three pairs. The adjusted mean score was calculated for the intervention groups and the control groups in the three pairs as also shown in Table 4. The overall adjusted mean knowledge score was 16.3 and 12.8 for the intervention and comparison schools respectively.

Table 5 shows an analysis of the covariance of attitude scores 1 year after intervention. The baseline attitude scores showed a significant influence in pair II; however, the main effect was due to intervention in this pair as well as in pair I. For pair IlI, the intervention showed no significant effect on the attitude score after one year $(P=0.56)$. The overall adjusted mean score was 7.9 for the intervention schools and 6.3 for comparison schools.

Schistosomal infection was reassessed 1 year after intervention. When the results were compared with that of baseline data, it was obvious that there was a reduction in the occurrence of schistosomal infection in 
Table 1 General characteristics of the study pairs

\begin{tabular}{|c|c|c|c|c|c|c|c|c|c|c|c|c|}
\hline \multirow[t]{3}{*}{ Characteristic } & \multicolumn{4}{|c|}{ Pair I } & \multicolumn{4}{|c|}{ Pair II } & \multicolumn{4}{|c|}{ Pair III } \\
\hline & \multicolumn{2}{|c|}{$\begin{array}{c}\text { Intervention } \\
(n=212)\end{array}$} & \multicolumn{2}{|c|}{$\begin{array}{c}\text { Control } \\
(n=154)\end{array}$} & \multicolumn{2}{|c|}{$\begin{array}{c}\text { Intervention } \\
(n=119)\end{array}$} & \multicolumn{2}{|c|}{$\begin{array}{c}\text { Control } \\
(n=149)\end{array}$} & \multicolumn{2}{|c|}{$\begin{array}{c}\text { Intervention } \\
\quad(n=91)\end{array}$} & \multicolumn{2}{|c|}{$\begin{array}{l}\text { Control } \\
(n=75)\end{array}$} \\
\hline & No. & $\%$ & No. & $\%$ & No. & $\%$ & No. & $\%$ & No. & $\%$ & No. & $\%$ \\
\hline \multicolumn{13}{|l|}{$\operatorname{sex}$} \\
\hline Male & 135 & 63.7 & 74 & 48.1 & 60 & 50.4 & 79 & 53.1 & 45 & 49.5 & 41 & 54.7 \\
\hline Fermale & 77 & 36.3 & 80 & 51.9 & 59 & 49.6 & 70 & 46.9 & 46 & 50.5 & 34 & 45.3 \\
\hline$\chi^{2}$ & \multicolumn{4}{|c|}{8.89} & \multicolumn{4}{|c|}{0.18} & \multicolumn{4}{|c|}{0.45} \\
\hline Pvalue & \multicolumn{4}{|c|}{$<0.01$} & \multicolumn{4}{|c|}{$>0.05$} & \multicolumn{4}{|c|}{$>0.05$} \\
\hline \multicolumn{13}{|c|}{ Father's education } \\
\hline Educated & 108 & 51.0 & 100 & 64.9 & 57 & 47.9 & 66 & 44.3 & 58 & 63.6 & 45 & 60.0 \\
\hline Illiterate & 104 & 49.0 & 54 & 35.1 & 62 & 52.1 & 83 & 55.7 & 33 & 36.4 & 30 & 40.0 \\
\hline$\chi^{2}$ & \multicolumn{4}{|c|}{7.12} & \multicolumn{4}{|c|}{0.35} & \multicolumn{4}{|c|}{0.24} \\
\hline$P$ value & \multicolumn{4}{|c|}{$<0.01$} & \multicolumn{4}{|c|}{$>0.05$} & \multicolumn{4}{|c|}{$>0.05$} \\
\hline Mother's educa & & & & & & & & & & & & \\
\hline Educated & 27 & 12.7 & 31 & 20.0 & 13 & 10.9 & 25 & 16.7 & 23 & 25.3 & 20 & 26.6 \\
\hline Illiterate & 185 & 87.3 & 123 & 80.0 & 106 & 89.1 & 124 & 83.3 & 68 & 74.7 & 55 & 73.4 \\
\hline$\chi^{2}$ & & 3. & & & & 1.8 & & & & 0.04 & & \\
\hline Pvalue & & $>0$ & & & & $>0$ & & & & $>0.05$ & & \\
\hline Father's occups & & & & & & & & & & & & \\
\hline Farmer & 139 & 65.6 & 76 & 49.1 & 84 & 70.6 & 104 & 69.8 & 54 & 59.3 & 51 & 68.0 \\
\hline Other & 73 & 34.4 & 78 & 50.9 & 35 & 29.4 & 45 & 30.2 & 37 & 40.7 & 24 & 32.0 \\
\hline$x^{2}$ & & 9 & & & & 0. & & & & 1.33 & & \\
\hline$P$ value & & $<0$ & & & & $>0$ & & t & & $>0.05$ & & \\
\hline Source of water & & & & & & & & & & & & \\
\hline Tap water & 85 & 40.0 & 50 & 36.4 & 28 & 23.5 & 35 & 23.5 & 31 & 34.1 & 36 & 48.0 \\
\hline Pump water & 127 & 60.0 & 98 & 63.6 & 91 & 76.5 & 114 & 76.5 & 60 & 65.9 & 39 & 52.0 \\
\hline$\chi^{2}$ & & 0. & & & & 0. & & & & 3.32 & & \\
\hline$P$ value & & $>0$ & & & & $>0$ & & & & $>0.05$ & & \\
\hline Toilet in house & & & & & & & & & & & & \\
\hline Yes & 203 & 95.8 & 136 & 88.3 & 114 & 95.8 & 130 & 87.1 & 88 & 96.7 & 71 & 94.7 \\
\hline No & 9 & 4.2 & 18 & 11.7 & 5 & 4.2 & 19 & 12.9 & 3 & 3.3 & 4 & 5.3 \\
\hline$x^{2}$ & & 7. & & & & 6. & & & & 0.42 & & \\
\hline$P$ value & & $<0$ & & & & $<0$ & & & & $>0.05^{\circ}$ & & \\
\hline Schistosomal in & & & & & & & & & & & & \\
\hline Positive & 58 & 27.4 & 35 & 2.7 & 17 & 14.3 & 18 & 12.1 & 9 & 9.8 & 9 & 12.0 \\
\hline Negative & 154 & 72.6 & 119 & 77.3 & 3102 & 85.7 & 13131 & 87.9 & 82 & 90.2 & 66 & 88.0 \\
\hline$\chi^{2}$ & & 1. & & & & 0.2 & & & & 0.19 & & \\
\hline$P$ value & & $>0$ & & & & $>0$ & & & & $>0.05$ & & \\
\hline
\end{tabular}

-Fisher exact test was used 
Table 2 Distribution of schoolchildren in the study pairs according to base-line knowledge and attitude scores

\begin{tabular}{|c|c|c|c|c|c|c|}
\hline \multirow[t]{2}{*}{ Baseline score } & \multicolumn{2}{|c|}{ Pair I } & \multicolumn{2}{|c|}{ Pair II } & \multicolumn{2}{|c|}{ Pair III } \\
\hline & $\begin{array}{l}\text { Intervention } \\
(n=212)\end{array}$ & $\begin{array}{c}\text { Control } \\
(n=154)\end{array}$ & $\begin{array}{c}\text { Intervention } \\
(n=119)\end{array}$ & $\begin{array}{c}\text { Control } \\
(n=149)\end{array}$ & $\begin{array}{l}\text { Intervention } \\
\quad(n=91)\end{array}$ & $\begin{array}{l}\text { Control } \\
(n=75)\end{array}$ \\
\hline \multicolumn{7}{|l|}{ Knowledge } \\
\hline Mean & 11.2 & 12.3 & 11.2 & 11.1 & 11.9 & 12.2 \\
\hline $\mathbf{s}$ & 2.9 & 2.7 & 2.4 & 2.4 & 2.5 & 2.5 \\
\hline$t^{a}$ & 3.5 & & 0.4 & & 0.81 & \\
\hline$P$ value & \multicolumn{2}{|c|}{$<0.001$} & \multicolumn{2}{|c|}{$>0.05$} & \multicolumn{2}{|c|}{$>0.05$} \\
\hline \multicolumn{7}{|l|}{ Attitude } \\
\hline Mean & 6.7 & 5.7 & 6.0 & 5.5 & 6.1 & 6.7 \\
\hline$s$ & 3.1 & 3.2 & 3.4 & 3.3 & 3.6 & 0.3 \\
\hline ta & 2.9 & & 1.3 & & 1.2 & \\
\hline$P$ value & \multicolumn{2}{|c|}{$<0.01$} & \multicolumn{2}{|c|}{$>0.05$} & \multicolumn{2}{|c|}{$>0.05$} \\
\hline
\end{tabular}

Student t-test; s = standard deviation

Table 3 Basellne and 1-month postintervention knowledge and attitude scores of schoolchildren in the intervention schools

\begin{tabular}{lcccc}
\hline Score & \multicolumn{2}{c}{ Knowledge } & \multicolumn{2}{c}{ Attitude } \\
& Mean & s & Mean & s \\
\hline Baseline & 11.3 & 2.3 & 6.4 & 3.3 \\
$\begin{array}{l}\text { One month post- } \\
\text { intervention }\end{array}$ & \multicolumn{1}{c}{18.6} & 2.3 & 9.5 & 2.7 \\
$t$ & \multicolumn{2}{c}{32.9} & \multicolumn{2}{c}{9.6} \\
Pvalue & $<0.001$ & & $<0.001$ \\
\hline
\end{tabular}

Paired t test $\mathrm{s}=$ standard deviation

both intervention and comparison schools of the three pairs (Table 6). However, the reduction was dramatic and statistically significant in the intervention schools of pairs I and II (the odds ratios were $0.57, P$ $<0.05$ and $0.23, P<0.02$, respectively). The overall odds ratio in the three intervention groups was $0.52,95 \% \mathrm{Cl}(0.49-0.55)$, $P<0.01$ and in the control groups was $0.78,95 \%$ CI $(0.49-1.25) P>0.05$.

\section{Discussion}

Innovative prevention approaches must be developed and implemented if we are to control schistosomal infection among schoolchildren. To our knowledge, this is the first report of a controlled study evaluating the role of a schistosomal health education model developed specifically for primary schonl children in Egypt.

The model involved various educational approaches including health talks, group discussions, case histories, stories and role playing, and was reinforced with a package of 32 slides. The effectiveness of the model in improving knowledge and attitude, as well as reducing schistosomal infection, was evaluated through a quasi-experimental design involving three pairs of comparable primary schools in Kaliubia Governorate. Despite its limitations, this design is economical, practical and useful for evaluating public health interventions $[1 I]$. Children in the intervention schools received the health education model combined with screening and treatment of 
Table 4 Analysis of covarlance of the knowledge scores 1 year after intervention

\begin{tabular}{|c|c|c|c|c|c|c|}
\hline \multirow[t]{2}{*}{ Sources of varlation } & \multicolumn{2}{|c|}{ Palr I } & \multicolumn{2}{|c|}{ Paìr H } & \multicolumn{2}{|c|}{ Pair ElI } \\
\hline & $F$ test & $P$ value & Ftest & Pvalue & Ftest & Pvalue \\
\hline Covariates & 1,4 & 0.24 & 1.1 & 0.38 & 0.6 & 0.65 \\
\hline Sex & 3.9 & 0.05 & 1.3 & 0.25 & 0.5 & 0.46 \\
\hline Father's education & 0.1 & 0.81 & 0.5 & 0.48 & 0.3 & 0.56 \\
\hline Toilet in house & 0.2 & 0.66 & 0.6 & 0.46 & 1.2 & 0.29 \\
\hline Baseline score & 2.5 & 0.12 & 1.5 & 0.22 & 0.4 & 0.55 \\
\hline Between groups & 75.0 & 0.0001 & 155.4 & 0.0001 & 16.8 & 0.0001 \\
\hline $\begin{array}{l}\text { Adjusted mean score: } \\
\text { Intervention } \\
\text { Control }\end{array}$ & & & & & & \\
\hline
\end{tabular}

Total adjusted mean knowledge score after 1 year: intervention groups $=16.3$; control groups $=12.8$

Table 5 Analysis of covariance for attitude scores 1 year after intervention

\begin{tabular}{|c|c|c|c|c|c|c|}
\hline \multirow[t]{2}{*}{ Sources of variation } & \multicolumn{2}{|c|}{ Pair I } & \multicolumn{2}{|c|}{ Pair II } & \multicolumn{2}{|c|}{ Pair III } \\
\hline & $F$ test & Pvalue & $F$ test & Pvalue & $F$ test & Pvalue \\
\hline Covariates & 1.1 & 0.34 & 1.9 & 0.12 & 0.6 & 0.64 \\
\hline Sex & 0.0 & 0.99 & 0.3 & 0.60 & 0.2 & 0.64 \\
\hline Father education & 0.9 & 0.35 & 3.3 & 0.07 & 1.7 & 0.20 \\
\hline Toilet in house & 0.01 & 0.93 & 0.6 & 0.45 & 0.5 & 0.46 \\
\hline Base-line score & 3.0 & 0.08 & 5.2 & 0.02 & 0.2 & 0.66 \\
\hline Between groups & 63.5 & 0.000 & 16.5 & 0.000 & 0.3 & 0.56 \\
\hline \multicolumn{7}{|l|}{ Adjusted mean score: } \\
\hline Intervention & \multicolumn{2}{|c|}{7.9} & \multicolumn{2}{|c|}{8.2} & \multicolumn{2}{|c|}{7.9} \\
\hline Control & \multicolumn{2}{|c|}{5.5} & \multicolumn{2}{|c|}{6.1} & \multicolumn{2}{|c|}{6.3} \\
\hline
\end{tabular}

Total adjusted mean attitude score after 1 year: intervention groups $=7.9 ;$ control groups $=6.3$

schistosomiasis. Those of the comparison schools were subjected to screening and treatment activities only which is the conventional strategy employed by Ministry of Health and Population of Egypt during the past few years. High coverage with safe water supply and sewage disposal was one of the criteria specified when the villages and schools of the study were selected.
Unfortunately, an increase in knowledge and favourable attitudes will not lead to behavioural changes untess the environmental facilities that influence the transformation of knowledge and attitudes into the desirable behaviour are assured [12].

The results of the study revealed a significant improvement in knowledge and attitude scores of the children in the 
Table 6 Pre-intervention to post-intervention changes of schistosomal infection in the study pairs

\begin{tabular}{lcccccccc}
\hline Pair School & \multicolumn{2}{c}{$\begin{array}{c}\text { Pre-intervention } \\
\text { infection }\end{array}$} & \multicolumn{2}{c}{$\begin{array}{c}\text { Post-intervention } \\
\text { infection }\end{array}$} & \multicolumn{3}{c}{$\begin{array}{c}\text { Pre-intervention to } \\
\text { post-intervention }\end{array}$} \\
\hline & & No. & $\%$ & No. & $\%$ & Odds ratlo & $(95 \%$ Cl) & Po \\
\hline I & I & 58 & 27.4 & 36 & 18.3 & 0.57 & $(0.35-0.94)$ & $<0.05$ \\
& C & 35 & 22.7 & 29 & 19.1 & 0.76 & $(0.40-1.46)$ & $>0.05$ \\
II & I & 17 & 14.3 & 7 & 6.3 & 0.23 & $(0.18-0.29)$ & $<0.02$ \\
& C & 18 & 12.1 & 15 & 10.8 & 0.75 & $(0.32-1.78)$ & $>0.05$ \\
III & I & 9 & 0.0 & 7 & 8.2 & 0.71 & $(0.62-0.82)$ & $>0.05$ \\
& C & 9 & 12.0 & 8 & 11.4 & 0.86 & $(0.29-2.60)$ & $>0.05$ \\
\hline
\end{tabular}

$I=$ Intervention, $C=$ comparison

'Based on McNemar test

Overall odds ratio: intervention groups $=0.52,95 \% \mathrm{Cl}(0.49,0.55), \mathrm{P}<0.01 ;$ control groups $=0.78,95 \% \mathrm{Cl}$ $(0.49,1.25), P>0.05$

intervention schools of pairs I and II one year following implementation of the health education model (Tables 4 and 5). There was also a parallel and significant reduction of schistosomal infections in the intervention schools of pairs I and II respectively (Table 6). The increase in the children's knowledge in the intervention school of pair III. however. was not coupled with either a significant improvement of attitude or a reduction of schistosomal infection.

Failure to document such changes might be due to the presence of social or environmental barriers which interfere with the establishment of favourable attitudes and habits. It is improbable that the implementation of the health education model was not intensive, that is, that a type III error occurred in the intervention school of pair III, as the nominated teachers were well trained regarding the use of the model [13]. In addition, health education sessions were supervised by a project team to ensure compliance with training guidelines and instruction. A type II error due to the relatively small number of children in pair III is. however. a possible explanation [14]. The role of measurement error due to weakness of the study instruments is also an unlikely explanation. Cronbach alpha coefficient was 0.84 and 0.73 for knowledge and attitude respectively, indicating adequate levels of the homogeneity for the used items. In addition, the items used in knowledge and attitude score were reviewed and validated by a group of experts. A selection bias due to dropouts in pair III is also unlikely as the number of children who were lost to follow-up was small ( $6.5 \%$ and $6.6 \%$ for intervention and comparison schools, respectively). In addition, the general characteristics of the children who dropped out did not differ from those who completed the study. Although the one year post-intervention knowledge and attitude scores were adjusted for the possible confounding effects of sex, the lack of the father's education and the availability of a toilet within the house, as well as the baseline score, the possibility of confounders not addressed in the study design cannot be ruled out, particularly in pair IIl.

The prevalence of schistosomal infestation declined from baseline to final survey in both intervention and control groups of the three pairs. However, the drop was dra- 
matic and statistically significant in the intervention groups of pairs I and II. Changes in the control groups, although nonsignificant in our study, have been described in other randomized studies $[15,16]$. Loevinsohn [7] explained this finding as the Hawthorn effect (the effect of being watched or unusual attention being paid to the control group).

In conclusion, the results of this study suggest that a sizable reduction of schistosomal infection may be achieved by inserting a relatively low-cost behavioural intervention programme into routine screening and treatment of schoolchildren. The developed health education model may prove to be suitable for use by the Ministry of Health and Population of Egypt. There is, however, a need for feasibility and cost- effectiveness analysis of the developed model in various endemic areas of Egypt.

\section{Acknowledgments}

This work was funded by research grant No. 10/15/90 from the Schistosomiasis Research Project (SRP) of the Ministry of Health and Population of Egypt and by the United States Agency for International Development (USAID) The authors would like to thank SRP and USAID for funding this work. We gratefully acknowledge Professor Aly Massoud, Professor Ahmed Sherif Hafez and Professor Mohsen Gadalla for their technical assistance and valuable comments.

\section{References}

1. El-Malatawy AE. Schistosomiasis control project of Beheira Governorate. Cairo, UNICEF, 1989.

2. UNICEF. Review of the programme of cooperation between the Arab Republic of Egypt and UNICEF. Cairo, UNICEF, 1990.

3. Mott KE. Schistosomiasis cantrol: everybody's business. Paper presented at the International Conference on Schistosomiasis, Cairo, Egypt, 14-18 February 1993.

4. Health education in the control of schistosomiasis. Gonova, World Health Organization, 1990.

5. Report of an independent evaluation mission on the National Bilharzia Control Program, Egypt, 1985, Transactions of the Royal Society of Tropical Medicine and Hygione, 1987, 81(euppl.):1-67.
6. Habib M et al. Schistosomiasis in Egypt: prevalence, intensity and morbidity in Qulubia Governorate. In: Proceedings of the International Conference on schistosomiasis, Cairo, Egypt, 14-18 February 1993. Cairo, Schislosomiasis Research Project, 1993.

7. Peters PAS, Warren KS, Mahmoud AAF, Rapid, accurate quantification of schistosome eggs via nucleopore filters. Journal of parasitology, 1976, 62:154-5.

8. Peters PAS, Kazura JW. Update on diagnostic methods for schistosomiasis. In: Mahmoud AAF, ed. Clinical tropical medicine and comunicable diseases. London, Baillière Tindall, 1987.

9. Loevinsohn BP. Health education interventions in developing countries: a methodological review of published articles. International journal of epidemiology, 1991, 19(4):788-94. 
10. Litwin MS. How to measure survey reliability and validity. London, Sage Publications, 1995.

11. Lilienfeld DE, Stolley PD. Foundations of epidemiology, 3rd ed. New York, Oxford University Press, 1994: 179-97.

12. Green LW et al. Health education planning: a diagnostic approach. Palo Alto, CA, USA, Maytield Press, 1980.

13. Basch CE et al. Type III errors in health oducation evaluations. Health education quarterty, 1985, 12:315-33.

14. Koepsell TD et al. Data analysis and sample size issues in evaluations of community-based health promotion and disease prevention programs: a mixedmodel analysis of variance. Journal of clinical epidemiology, 1991, 44:701-13.

15. Ross SM, Loening WE, Van Middelkoop A. Breast-feeding: evaluation of a health education programme. South African medical journal, 1983, 64:361-3.

16. Stanton BF, Clemens JD. An educational intervention for altering water sanitation behaviors to reduce childhood diarrhea in urban Bangladesh. II. A randomized trial to assess the impact of intervention on hygienic behaviors and rates of diarrhea. American journal of epidemiology, 1987 , 125:292-301.

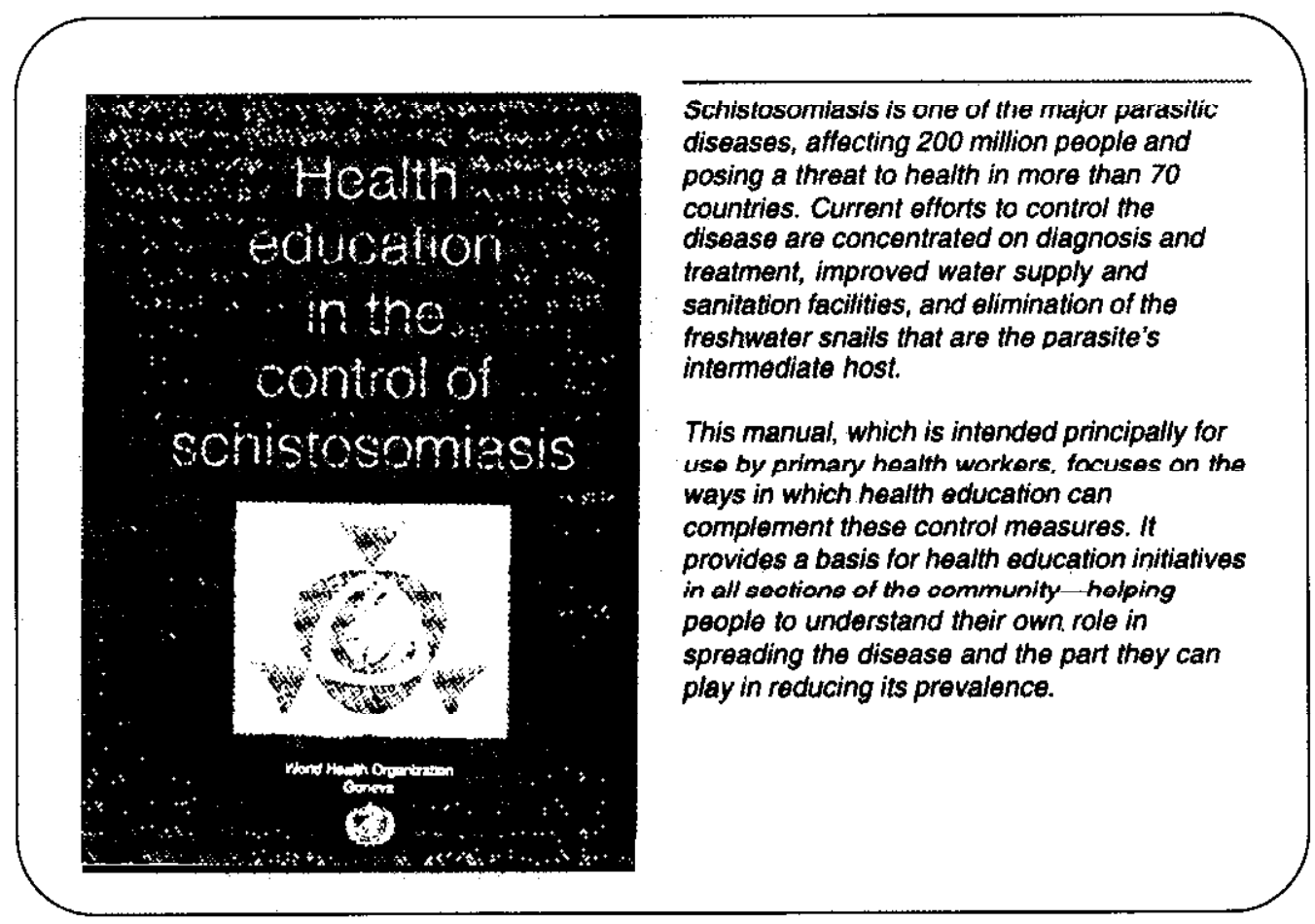

This publication can be ordered from Distribution and Sales Unit, World Health Organization, 1211 Geneva 27, Switzerland. Telephone: +4122791 2476; fax: +41227914857.

Price: Sw.fr. 11.- (in devoloping oountrios: Sw.fr. 7.70)

It will be available in Arabic from the Regional Office for the Eastern Mediterranean in 1998. 